\title{
Evaluation of mHealth Apps for Diverse, Low-Income Patient Populations: Framework Development and Application Study
}

Shreya Sharma ${ }^{1,2}$, MD; Katherine Gergen Barnett ${ }^{3,4}$, MD; John (Jack) Maypole ${ }^{5,6}$, MD; Rebecca Grochow Mishuris ${ }^{7,8}$, $\mathrm{MD}, \mathrm{MPH}$

\author{
${ }^{1}$ Boston University School of Medicine, Boston, MA, United States \\ ${ }^{2}$ Beth Israel Deaconess Medical Center, Boston, MA, United States \\ ${ }^{3}$ Department of Family Medicine, Boston Medical Center, Boston, MA, United States \\ ${ }^{4}$ Department of Family Medicine, Boston University School of Medicine, Boston, MA, United States \\ ${ }^{5}$ Department of Pediatrics, Boston Medical Center, Boston, CA, United States \\ ${ }^{6}$ Department of Pediatrics, Boston University School of Medicine, Boston, MA, United States \\ ${ }^{7}$ Department of Medicine, Boston Medical Center, Boston, MA, United States \\ ${ }^{8}$ Department of Medicine, Boston University School of Medicine, Boston, MA, United States
}

\section{Corresponding Author:}

Shreya Sharma, MD

Boston University School of Medicine

72 E Concord Street

Boston, MA, 02118

United States

Phone: 1 (617)358 9600

Email: sshreya@bu.edu

\section{Abstract}

Background: The use of mobile technology or smartphones has grown exponentially in the United States, allowing more individuals than ever internet access. This access has been especially critical to households earning less than US $\$ 30,000$, the majority of whom indicate that smartphones are their main source of internet access. The increasing ubiquity of smartphones and virtual care promises to offset some of the health disparities that cut through the United States. However, disparities cannot be addressed if the medical information offered though smartphones is not accessible or reliable.

Objective: This study seeks to create a framework to review the strengths and weaknesses of mobile Health (mHealth) apps for diverse, low-income populations.

Methods: Focusing on smoking cessation, diabetes management, and medication adherence as models of disease management, we describe the process for selecting, evaluating, and obtaining patient feedback on mHealth apps.

Results: The top 2 scoring apps in each category were QuitNow! and Smoke Free-Quit Smoking Now for smoking cessation, Glucosio and MyNetDiary for diabetes management, and Medisafe and MyMeds for medication adherence.

Conclusions: We believe that this framework will prove useful for future mHealth app development, and clinicians and patient advisory groups in connecting culturally, educationally, and socioeconomically appropriate mHealth apps with low-income, diverse communities and thus work to bridge health disparities.

(JMIR Form Res 2022;6(2):e29922) doi: 10.2196/29922

\section{KEYWORDS}

mobile health application; apps; mobile health; diverse; low-income; mHealth; framework; chronic disease; condition; smoking cessation; diabetes; medication adherence; safety net hospital; personal; self-management; usability test

\section{Introduction}

The use of mobile technology has grown exponentially in the United States, and the COVID-19 pandemic both enforced the

need for internet connectivity and laid bare disparities in access. Currently, up to $97 \%$ of Americans own a cell phone, including $97 \%$ of those with a household income under US \$30,000 [1]. However, $27 \%$ of households earning under US $\$ 30,000$ rely on smartphones for internet access, compared to only $6 \%$ of 
households earning greater than US \$100,000 [2]. During the COVID-19 pandemic, $43 \%$ of individuals used their cell phones to manage mental health and well-being, $41 \%$ to access health care, and $40 \%$ to keep fit and exercise [3]. While there still remains a large socioeconomic digital divide, the increasing ownership of ever-evolving smartphones and their functionality may partially offset this disparity [4,5].

The mobile health (mHealth) app market has flourished as consumers, health technology companies, and biomedical researchers have recognized mobile apps as a potential vehicle to lower barriers to accessing preventive medicine and promoting healthy behaviors. This extends to lower-income populations as well [6]. Currently, there are a total of 48,608 mHealth apps available for download in the Apple App Store [7]. The mHealth app industry is forecasted to be worth US $\$ 151$ billion by $2025[8,9]$. However, little is known about efficacy of these apps, particularly across diverse consumer (and patient) populations.

The COVID-19 pandemic has illuminated the long prevalent health disparities among lower-income populations who experience higher rates of chronic disease such as diabetes and hypertension [10]. Mobile apps could, in theory, address some of these disparities. Indeed, mobile health apps have been proven, in many instances, to impact lifestyle changes and health outcomes positively $[11,12]$. There are available mobile health apps that promote healthy behaviors (such as exercise or smoking cessation) and support chronic disease management (such as monitoring blood sugar levels and enhancing medication adherence). Patients in diverse, low-income communities have shown more interest than white, high-income communities in the use of mHealth apps, particularly for chronic disease and overall health management [13-15]. This presents an area of opportunity for software developers and health care providers to reduce health inequities. However, the vast majority of mHealth apps do not cater to the needs of lower-income populations, as they have been shown to be difficult to navigate for individuals who may have limited health, digital, or written literacy [11,16-20]. Additionally, there is no universally accepted framework to assess the functionality and usability of mHealth apps, which may further disproportionately impact diverse, low-income populations [6,12].

This study seeks to create a framework for the evaluation of mHealth apps' accessibility for diverse, low-income populations. We developed and tested a rubric (a guide listing specific criteria for grading or scoring) of domains (features of mHealth apps with a common purpose) to measure the functionality and usability of several mHealth apps for patients of an urban safety net institution. Focusing on smoking cessation, diabetes management, and medication adherence as models of disease management, we describe the process of selection of domains of mHealth apps, development of the rubric, and scoring of various mHealth apps. We envision that this framework will prove useful for clinicians, care teams, patient advisory groups, and developers (who seek to design apps with equitable reach and greater impact on health outcomes) in connecting culturally, educationally, and socioeconomically appropriate mHealth apps with communities historically overlooked by this rapidly evolving area of health care.

\section{Methods}

\section{Domain Selection}

In June 2018, we searched web-based databases (PubMed and Embase) to identify articles related to the evaluation of the usability of mobile apps for health and wellness. Studies from this literature review were assessed to create a list of domains for rating mHealth apps relevant to diverse, low-income populations. Search criteria included "smartphone application underserved community," "usability of commercially available applications for diverse patients," "mHealth apps usability testing underserved," "mheatlh app underserved," "mobile health phone applications for diverse populations," on PubMed and "mobile application'/exp OR 'mobile application' OR 'mobile phone'/exp OR 'mobile phone," “"mHealth under-served' OR (('mhealth'/exp OR mhealth) AND unders-erved)" on Embase.

An extensive literature review indicated important domains of mHealth apps for our target population, including the following: language, literacy, graphics, multimedia, usability, patient-centeredness, data entry mode, data exportability, cost, evidence based content, platform, extent to which the platform was up to date, connectivity, Americans with Disabilities Act (ADA) accessibility, privacy, social network, cultural sensitivity (incorporating diversity in language, graphics, and data), messaging or reminder capability, and benchmarking (comparing a user's performance to the performance of others on the app). These domains were grouped into larger categories, including the following: Usability (graphics, multimedia, usability, and ADA accessibility), Population focus (language, literacy, patient-centeredness, cost, social network, cultural sensitivity, benchmarking, and messaging or reminder capability), Technology (data entry mode, data exportability, platform, connectivity requirement, and privacy), and Clinical Impact (evidence-based content and extent to which the platform was up to date).

Each domain was then weighted in terms of importance to the target population by independent coders (RGM, KGB, and JM). These coders are all primary care physicians at an urban safety net hospital (in General Internal Medicine, Family Medicine, and Pediatrics, each with 10-25 years of experience at this institution) and care for overlapping members of these communities by age. They were asked to rate each domain on a scale of 1 to 5 (1="not important to be included" and 5="must be included"). Then, a reviewer (SS) adjudicated these weights and averaged the "weight" of each domain respectively. Finally, these weights were directionally confirmed with the hospital-based patient and family advocacy committee.

\section{App Selection}

To simulate how patients would access recommendations for mHealth apps, we used the most common search engine, Google, to search "Top Ten Mobile Health Apps for Diabetes" and "Top Ten Mobile Health Apps for Smoking Cessation." The first search result referred to articles in a popular health website "Healthline," which provided the top 10 mobile health apps related to each topic [21,22]. The website rated these apps on the basis of quality, reliability, reviews, and community nominations. As no such list existed for medication adherence 
focused apps, these apps were chosen from the list recommended by a previous study [23]. We chose apps in these 3 areas because they represent different aspects of medical care delivery: preventative care (smoking cessation), chronic disease management (diabetes management), and general therapeutic intervention (medication adherence).

\section{App Scoring}

Ten apps in smoking cessation, diabetes management, and medication adherence were identified and rated by a coder (SS) in each domain (language, literacy, graphics, multimedia, usability, patient-centered, data entry mode, data exportability, cost, evidence-based content, platform, extent the platform was up to date, connectivity, ADA accessibility, privacy, social network, cultural sensitivity, messaging or reminder capability, and benchmarking) with a score of 0 to 3. A score of 0 was assigned if the specific domain was not applicable, and a score of 3 was assigned for the highest applicability (eg, language_-available in 3 or more languages; Table 1). Domains were defined on the basis of current research in each respective domain. For example, for "Social Network," higher points were assigned for "competition" than for "social support" because previous studies have shown that social comparison was more important for physical activity [24]. As another example, the definition for "Usability" was based on the design of the app and the ability to navigate it easily. We specifically did not use the industry standard assessment (ie, System Usability Scale) owing to concerns about the applicability for diverse, low-socioeconomic status communities. Lastly, we decided whether apps were "evidence based" if they cited specific research or if the theory underlying their apps had existing evidence (ie, gasification and social networks).

The domain score was multiplied by the domain weight (of importance to the target population) to produce a weighted final score for that domain for the app in question. The weighted scores across all domains were added to assign each app a final overall score of usefulness and applicability for diverse, low-income populations. 
Table 1. Domain definitions and scoring.

\begin{tabular}{lllll}
\hline Domain & Points & & & \\
& 0 & 1 & 2 & 3
\end{tabular}

\section{Population focus}

Language Not applicable/not offered by app/not a function of this app

Literacy Not applicable/not offered by app/not a function of this app teredness app/not a function of this app

Social net- Not applicable/not offered by work app/not a function of this app

Benchmarking Not applicable/not offered by app/not a function of this app

Cultural sensi- N/A ${ }^{a}$

tivity

Cost

Not applicable/not offered by app/not a function of this app

Messages or Not applicable/not offered by reminders
Patient-cen- Not applicable/not offered by

Only available in English

Complex language, mediapp/not a function of this app lored to the user

Usability

Graphics

Multimedia Not applicable/not offered by

Not applicable/not offered by app/not a function of this app app/not a function of this app

Usability

Americans

with Disabilities Act acces-

sibility

Technology

Data entry

mode

Not applicable/not offered by app/not a function of this app

Data exporta- Not applicable/not offered by bility

Connectivity requirement app/not a function of this app

Not applicable/not offered by app/not a function of this app

Platform

Not applicable/not offered by app/not a function of this app

Privacy

\section{Clinical impact}

Evidence- Not applicable/not offered by based content
Not applicable/not offered by app/not a function of this app app/not a function of this app cal jargon

Does not allow patient-entered data/provides no tailored content

Provides a forum for people to share information/discuss different topics

Provides no sense of patient status among peers

No attempt at cultural diversity

Paid app

Has messages, but not tai- App has motivational mes-

Only text

No use of audio or video

Complex app navigation, small icons, multiple screens, not immediately obvious how to use

No accommodation for vi- Accommodation for visual or

sual or hearing impairment hearing impairment sages tailored to the user/reminders pop-up, but only if the user is on the app

Text $>$ graphics

Uses audio or video

Small icons, multiple screens, Large icons, few screens, easy to simpler app navigation but navigate without instruction/mostill would require instruction bile literacy

Accommodation for both visual and hearing impairment
Manual entry or integrated with information from the phone/other devices

Does not allow data export

Requires constant Wi-

$\mathrm{Fi} /$ cellular connection

Only iOS

No privacy statement

Some content has an evidence base

Allows export of data to print or email or message

Some functions useful without connection

No clear identification of evidence for content patient-friendly language at or below 5 th grade reading level

Provides actionable content based on patient-entered data

Incorporates a forum and also a "competition" between users

Allows patients to define peer groups for benchmarking

Cultural diversity definitely represented

Free app

App has option for you to "turn on notification" to receive reminders, messages, and notifications tailored specifically to the user

Graphics clearly explain the text

Uses audio and video integrate with external devices/sysor electronic health records

Fully functional without connection/only requires connection to tem

iOS and android

Integrated with external devices or electronic health records

Privacy statement exists
Entire app content is evidencebased 


\begin{tabular}{rllll}
\hline Domain & Points & 1 & 2 & 3 \\
\hline Up to date & $\begin{array}{l}\text { Not applicable/not offered by } \\
\text { app/not a function of this app }\end{array}$ & $\begin{array}{l}\text { No indication of last up- } \\
\text { date date/ updated }>18 \\
\text { months ago }\end{array}$ & $\begin{array}{l}\text { Updated within the last 12-18 } \\
\text { months }\end{array}$ & Updated within last 6-12 months \\
\hline
\end{tabular}

${ }^{\mathrm{a}} \mathrm{N} / \mathrm{A}$ : not applicable.

\section{Patient Advisory Board}

In July 2019, after the mHealth apps were chosen and scored, we presented the top 3 apps in each health category to a patient advisory board at a safety net hospital in Boston, Massachusetts. The group consisted of 4 participants on the day of presentation. They were Caucasian women between 35 and 75 years of age from the catchment area of the safety net institution. They were asked to give their overall thoughts on our research idea and the functionality of mHealth apps they considered important to manage their health on a daily basis.

\section{Results}

\section{Domain Scoring}

Domains of usability and functionality for mHealth apps were assigned weighted scores depending on the importance the clinical experts gave to those categories for diverse, low-income communities. These were directionally confirmed with a patient advisory board. Domains of greatest importance were identified through this process (Table 2). Literacy was found to be the highest scoring domain by clinical experts, with all raters assigning a score of 5 out of 5. Language, usability, cost, evidence based content, and cultural sensitivity had an average weight of 4.5 out of 5. Graphics was rated 4 out of 5. Social media connectivity and timing of the app's latest update were assigned a score of 3.5 out of 5. Multimedia, data exportability, patient centeredness, benchmarking, and messages or reminders were all rated an average of 3 out of 5. ADA accessibility was rated 2.5 out of 5 . Data entry and privacy domains were weighted 2 out of 5 , being the least important for the specific patient population. Raters were within 1 point of each other on all domains, with 8 out of 19 domain weightings being identical. The higher-level categories into which domains can be grouped also differentiated in terms of importance, with clinical impact and population focus being most highly weighted: Clinical Impact (average weight across component domains 4), Population Focus (average weight across component domains 3.88), Usability (average weight across component domains 3.5), and Technology (average weight across component domains 2.8). 
Table 2. Domains of greatest importance.

\begin{tabular}{|c|c|}
\hline Domain & Average final weight \\
\hline \multicolumn{2}{|l|}{ Population focus } \\
\hline Literacy & 5 \\
\hline Language & 4.5 \\
\hline Cultural sensitivity & 4.5 \\
\hline Cost & 4.5 \\
\hline Graphics & 4 \\
\hline Social network & 3.5 \\
\hline Patient-centeredness & 3 \\
\hline Benchmarking & 3 \\
\hline \multicolumn{2}{|l|}{ Usability } \\
\hline Usability & 4.5 \\
\hline Multimedia & 3 \\
\hline Messages or reminders & 3 \\
\hline Americans with Disabilities Act accessibility & 2.5 \\
\hline \multicolumn{2}{|l|}{ Technology } \\
\hline Platform & 4 \\
\hline Data exportability & 3 \\
\hline Connectivity requirement & 3 \\
\hline Data entry mode & 2 \\
\hline Privacy & 2 \\
\hline \multicolumn{2}{|l|}{ Clinical impact } \\
\hline Evidence-based content & 4.5 \\
\hline Up to date & 3.5 \\
\hline
\end{tabular}

\section{App Scoring}

When using the weighted scoring methodology to rate mHealth apps across smoking cessation, diabetes management, and medication adherence, the framework was able to sufficiently distinguish among 10 apps within each category (Table 3). Weighted scores ranged from 108.5 to 153 for smoking cessation apps, 119 to 147 for diabetes management apps, and 113 to 137.5 for medication adherence apps (Table 4). The top 2 scoring apps in each category were QuitNow! (156/201), Smoke Free-Quit Smoking Now (149.5/201), Glucosio (147/201), MyNetDiary (146/201), Medisafe (137.5/201), and MyMeds (126/201) (Multimedia Appendix 1). 
Table 3. Weighted scores for each top mobile app.

\begin{tabular}{|c|c|c|c|c|c|c|}
\hline & \multicolumn{2}{|c|}{ Smoking cessation } & \multicolumn{2}{|c|}{ Diabetes management } & \multicolumn{2}{|c|}{ Medication adherence } \\
\hline & QuitNow! & $\begin{array}{l}\text { Smoke Free- Quit } \\
\text { Smoking Now }\end{array}$ & MyNetDiary & Glucosio & Medisafe & My Meds \\
\hline Rating on app store (out of 5) & 4.6 & 4.8 & 4.6 & $\mathrm{~N} / \mathrm{A}^{\mathrm{a}}$ & 4.7 & N/A \\
\hline Ratings, $\mathrm{n}$ & 317,000 & 181,000 & 107,000 & N/A & 138,000 & N/A \\
\hline Language (4.5) & 13.5 & 13.5 & 4.5 & 13.5 & 3 & 1 \\
\hline Literacy (5) & 15 & 15 & 15 & 15 & 15 & 15 \\
\hline Graphics (4) & 8 & 12 & 12 & 12 & 12 & 12 \\
\hline Multimedia (3) & 3 & 6 & 6 & 3 & 3 & 3 \\
\hline Usability (4.5) & 13.5 & 13.5 & 9 & 13.5 & 13.5 & 13.5 \\
\hline Patient- centeredness ( 3 ) & 6 & 9 & 9 & 3 & 9 & 3 \\
\hline Data entry mode (2) & 2 & 2 & 4 & 2 & 6 & 2 \\
\hline Data exportability (3) & 6 & 6 & 9 & 6 & 6 & 3 \\
\hline Cost (4.5) & 9 & 9 & 6 & 13.5 & 9 & 13.5 \\
\hline Evidence-based content (4.5) & 13.5 & 13.5 & 13.5 & 4.5 & 0 & 0 \\
\hline Platform (4) & 12 & 12 & 12 & 12 & 12 & 12 \\
\hline Up to date (3.5) & 10.5 & 10.5 & 10.5 & 10.5 & 10.5 & 10.5 \\
\hline Connectivity requirement (3) & 6 & 6 & 6 & 9 & 9 & 9 \\
\hline $\begin{array}{l}\text { Americans with Disabilities Act acces- } \\
\text { sibility (2.5) }\end{array}$ & 2.5 & 2.5 & 2.5 & 2.5 & 2.5 & 2.5 \\
\hline Privacy (2) & 6 & 6 & 6 & 6 & 6 & 6 \\
\hline Benchmarking (3) & 6 & 3 & 3 & 3 & 3 & 3 \\
\hline Social support (3.5) & 3.5 & 0 & 3.5 & 0 & 0 & 3.5 \\
\hline Cultural sensitivity (4.5) & 4.5 & 4.5 & 13.5 & 9 & 9 & 4.5 \\
\hline Messages (3) & 9 & 9 & 9 & 9 & 9 & 9 \\
\hline
\end{tabular}

${ }^{\mathrm{a}} \mathrm{N} / \mathrm{A}$ : not applicable.

Table 4. Weighted scores of top mobile apps.

\begin{tabular}{lll}
\hline App name & Cumulative final score & Range of final scores across all 10 apps evaluated \\
\hline $\begin{array}{l}\text { Smoking cessation } \\
\text { Smoke Free-Quit Smoking Now }\end{array}$ & 153 & $108.5-153$ \\
$\quad$ QuitNow! & 146.5 & \\
Diabetes management & 147 & $122-147$ \\
$\quad$ Glucosio & 146 & $113-137.5$ \\
$\quad$ MyNetDiary & 137.5 & \\
Medication adherence & 126 & \\
Medisafe & & \\
My Meds &
\end{tabular}

\section{Discussion}

\section{Principal Findings}

mHealth apps have the potential to improve individuals' management of chronic diseases and to extend the reach of the health care provider visit. Considering the increasing predominance of smart device use to access the internet among diverse, low-income communities, mHealth apps hold enormous potential for impact on health and could help bridge health equity divides. To date, however, studies have shown that more research is needed to rate the practical functionality of these mobile apps, specifically for this target population $[25,26]$. By developing a framework to rate the usefulness of mHealth 
applications for low income, diverse, patient populations, and showing its effectiveness to differentiate between apps, we aimed to provide a way to curate mHealth apps for better access and engagement among diverse populations.

Existing frameworks such as the Mobile App Rating Scale (MARS) include ratings for domains grouped into categories with broad population applicability, including engagement, functionality, aesthetics, subjective quality, and information. As identified by researchers who created the MARS system, this grading system is agnostic to the needs of specific populations and may not be indicative of the usefulness of apps for specific groups. As a result, it is difficult to apply the grading criteria of MARS to diverse, low-income patient populations [26]. The evaluation mechanism described in this study incorporates domains that are applicable for general consumption as contained in MARS and highlighted by Anderson et al [27] and others as important to engagement ("evidence based content," "privacy," "up to date," "patient centered," "benchmarking," and "social network"), but expands beyond MARS specifically for diverse, low-income patient populations [26-29].

In contrast to the more generalized domains, our research led us to evaluate a greater number of criteria with population-specific focus. The domains expanded upon those in the MARS criteria to include: language, literacy, cultural sensitivity, data entry, data exportability, multimedia, ADA accessibility, cost, platform, and message or reminder function. As identified by prior studies, multimedia availability, such as videos, helped increase mobile app engagement, particularly for individuals with low literacy levels [16,17,19,20,30,31]. Messages or a reminder function helped app users stay motivated in their plan, manage medications, and organize personal health information [29,32-36]. Cost was a domain included in our scoring framework because some past studies showed increased engagement if patients paid for the app. However, there is a question as to whether this would be an undue barrier for patients with low income [27]. Importantly and consistent with our hypothesis, language, literacy, and cultural sensitivity were found to be some of the most important qualities for an app to have to be relevant and useful for diverse, low-income populations, according to both our clinician and patient reviewers [14,16,18-20,29,37-40].

The highest rated mHealth apps in our sample shared notable, similar qualities, regardless of what chronic illness or health state they were developed to manage. Most apps placed importance on offering multiple languages, being written for lower literacy levels, and incorporating graphics; these scored high on usability. However, apps such as MyNetDiary, for diabetes management, which were more difficult to navigate, did offer additional resources to learn about navigating through the app, such as an instructional video. Additionally, privacy, evidence-based content, data entry, data exportability, and patient-centered content were present in most (but not all) of the chosen apps. Benchmarking (comparing a user's performance to the performance of others on the app), social support networks, and multimedia use scores were not robust in any of the chosen apps. ADA accessibility and cultural sensitivity (incorporating diversity in language, graphics, and data) were also lacking. Based on these results, the apps rated most highly in accordance with our framework conveyed information in a manner that a more diverse user base would be able to effectively engage with. However, as a whole, the mobile apps did not focus any specific attention to engaging a diverse population. For example, although many apps were inclusive by providing multiple language options, they lacked content that was tailored to a culturally diverse population. Overall, although these apps were the best of what is currently on the market, they are far from being ideal for our target population.

The patient advisory board was both a versatile and key feature of our research effort providing both a patient perspective on the mHealth apps and on the domains included in the framework we developed. Thus, we gained insight to patients' perspectives and were able to compare their priorities in engaging with these apps to those of health care providers in the same system. Domains including language, literacy, evidence-based content, cultural sensitivity, and providing up-to-date information were ranked highly by both groups. However, some domains such as graphics, social network, and benchmarking were not as important to patients as they were thought to be by providers. In contrast to our qualitative findings, prior studies have shown that apps with simple interfaces that favor graphics over text tend to be more usable with lower literacy populations [19,37]. Additionally, social media functionality has also been found to reduce barriers to sharing information and learning from others $[32,41,42]$. Therefore, while other studies have shown these domains to be important to engagement, our patients did not rank them highly in terms of importance to usability. These differences could be explained by the small sample size and demographics of our patient advisory group.

\section{Limitations}

There were several limitations to this work, which can be used as learning points for future research. First, in selecting which mHealth apps to evaluate we used a common website which had its own subjective way of choosing which apps were the "best." However, this approach to finding the "top 10" apps on a website likely replicates the way in which patients would search for and find mHealth apps to download and use. The mHealth app market is in a constant state of flux and growth, and with it, the "top 10." Second, some of the mHealth apps initially identified for evaluation were not available for download. Churn in the mHealth market may impact engagement with some mHealth apps. However, this better reflected which mHealth apps would be accessible to our patients. Third, as this was a small study with no independent funding, we only had one reviewer grade the mHealth apps across each domain. Though individual user subjectivity is inherently part of the process of evaluating mHealth apps, this process may result in some subjectivity to our analysis of the individual apps. Furthermore, our patient advisory board was not necessarily representative of the diverse patient population of the hospital. While they themselves were patients at the safety net institution, they were all White women aged 35-75 years. As a result, their opinions may not be generalizable and could be subject to conscious and unconscious biases. While this limitation is significant, we also found it important to have some 
patient perspective and validation rather than none at all. Finally, it is important to acknowledge our mHealth rubric and research was conducted before the COVID-19 pandemic, and much of mHealth has evolved since then. Our reliance on technology is more than ever, and we may be more dependent on mobile app technologies. However, the nature of this research should withstand the evolution of the mHealth app market, and even seek to improve upon it as it can be applied to make this growing field even more accessible for a diverse user base.

\section{Conclusions}

We adapted a framework for evaluating mHealth apps for diverse, low-income populations from the MARS model and created modified domains to characterize critical features as identified by patients and clinical experts who care for these patient populations. Although these app domains are rated separately, it is important to remember that often these different domains work synergistically. Some domains may increase user engagement and retention while others are focused on increasing access, inclusivity, or privacy. Multiple languages remain a worthy goal, but we contend mHealth app developers should also consider incorporating culturally sensitive and specific information such as recipes, videos, and motivational tools.

This novel framework is invaluable as it can be applied to evaluate individual mHealth apps in the context of therapeutic interventions, as well as by app developers to identify those domains important for engagement of diverse, low-income populations. However, right now our app ranks relative performance. To establish specific scoring thresholds and determine cut-off ratings for apps we need to apply this rating framework to a large number of apps. The plan would be to accomplish this during a follow-up study. For now, we believe distinguishing relative performance is important so developer can use an iterative approach to design apps. They can use scores as a performance indicator as they improve or refine existing apps. If developers are able to report app performance, it may be a way to filter apps and create inter-app competition to improve performance.

\section{Future Prospects}

In the future, the study team plans to incorporate the selected apps in smoking cessation, diabetes management, and medication adherence into our clinical processes as "prescriptions" for patients. We will be able to track these "prescriptions," assess patient engagement, and determine impact on health outcomes. In addition, we hope to continue to use our framework to find, scale, and spread mHealth apps that will be most useful for our target population in other areas of health including exercise and mental health. By using this novel framework to identify mHealth apps for recommendation and for future mHealth app development, health care providers, policy makers and developers alike may be able to better incorporate this burgeoning technology into both clinical practice and patient homes for greater impact on health outcomes for all patients, further narrowing digital and health outcome divides.

\section{Conflicts of Interest}

None declared.

\section{Multimedia Appendix 1}

Domain Definitions and Scoring.

\section{[DOCX File, 37 KB-Multimedia Appendix 1]}

\section{References}

1. Mobile Fact Sheet. Pew Research Center. 2021 Apr 07. URL: https://www.pewresearch.org/internet/fact-sheet/mobile/ [accessed 2022-01-26]

2. Vogels EA. Digital divide persists even as Americans with lower incomes make gains in tech adoption. Pew Research Center. 2021 Jun 22. URL: https://www.pewresearch.org/fact-tank/2021/06/22/ digital-divide-persists-even-as-americans-with-lower-incomes-make-gains-in-tech-adoption/ [accessed 2022-01-26]

3. Engebreston J. COVID-19 Mobile Usage Increased One Hour a Day; Consumers Value ICT, Report Says. Telecompetitor. 2020 Jun 16. URL: https://www.telecompetitor.com/ covid-19-mobile-usage-increased-one-hour-a-day-consumers-value-ict-report-says/ [accessed 2022-01-26]

4. Smith A. African Americans and Technology Use: A Demographic Portrait. Pew Research Center. 2014 Jan 06. URL: https://www.pewresearch.org/internet/2014/01/06/african-americans-and-technology-use/ [accessed 2020-05-20]

5. Smith A. Technology Trends Among People of Color. Pew Research Center. 2010 Sep 17. URL: https://www. pewresearch.org/internet/2010/09/17/technology-trends-among-people-of-color/ [accessed 2020-05-20]

6. Vangeepuram N, Mayer V, Fei K, Hanlen-Rosado E, Andrade C, Wright S, et al. Smartphone ownership and perspectives on health apps among a vulnerable population in East Harlem, New York. Mhealth 2018;4:31 [FREE Full text] [doi: 10.21037/mhealth.2018.07.02] [Medline: 30221166]

7. Number of mHealth apps available in the Apple App Store from 1st quarter 2015 to 1st quarter 2021. Statista. URL: https:/ /www.statista.com/statistics/779910/health-apps-available-ios-worldwide/ [accessed 2022-01-26]

8. The global mHealth market size is expected to reach USD 151.57 billion by 2025 , progressing at a CAGR $25.7 \%$ over the forecast period. Cision US. URL: https://tinyurl.com/nxr4y3mx [accessed 2022-01-26] 
9. MHealth Market Analysis Report By Participants, By Service And Segment Forecasts, 2018 - 2025. ReportLinker. URL: https://www.reportlinker.com/p05741285/mHealth-Market-Analysis-Report-By-Participants-By-Service-And-SegmentForecasts.html?utm source=PRN [accessed 2022-01-26]

10. 2016 National Healthcare Quality and Disparities Report. Agency for Healthcare Research and Quality. URL: https://www. ahrq.gov/research/findings/nhqrdr/nhqdr16/index.html [accessed 2020-05-20]

11. Marcolino MS, Oliveira JAQ, D'Agostino M, Ribeiro AL, Alkmim MBM, Novillo-Ortiz D. The Impact of mHealth Interventions: Systematic Review of Systematic Reviews. JMIR Mhealth Uhealth 2018 Jan 17;6(1):e23 [FREE Full text] [doi: 10.2196/mhealth.8873] [Medline: 29343463]

12. Free C, Phillips G, Galli L, Watson L, Felix L, Edwards P, et al. The effectiveness of mobile-health technology-based health behaviour change or disease management interventions for health care consumers: a systematic review. PLoS Med 2013;10(1):e1001362 [FREE Full text] [doi: 10.1371/journal.pmed.1001362] [Medline: 23349621]

13. Humble JR, Tolley EA, Krukowski RA, Womack CR, Motley TS, Bailey JE. Use of and interest in mobile health for diabetes self-care in vulnerable populations. J Telemed Telecare 2016 Jan;22(1):32-38. [doi: 10.1177/1357633X15586641] [Medline: 26026179]

14. Ramirez V, Johnson E, Gonzalez C, Ramirez V, Rubino B, Rossetti G. Assessing the Use of Mobile Health Technology by Patients: An Observational Study in Primary Care Clinics. JMIR Mhealth Uhealth 2016 Apr 19;4(2):e41 [FREE Full text] [doi: 10.2196/mhealth.4928] [Medline: 27095507]

15. Purnell JQ, Griffith J, Eddens KS, Kreuter MW. Mobile technology, cancer prevention, and health status among diverse, low-income adults. Am J Health Promot 2014;28(6):397-402 [FREE Full text] [doi: 10.4278/ajhp.120816-ARB-396] [Medline: 24200336]

16. Sarkar U, Gourley GI, Lyles CR, Tieu L, Clarity C, Newmark L, et al. Usability of Commercially Available Mobile Applications for Diverse Patients. J Gen Intern Med 2016 Dec;31(12):1417-1426 [FREE Full text] [doi: 10.1007/s11606-016-3771-6] [Medline: 27418347]

17. Vu M, Nguyen V, Vishwanath S, Wolfe C, Patel S. Know Your Numbers: Creation and implementation of a novel community health mobile application (app) by student pharmacists. J Am Pharm Assoc (2003) 2018;58(2):191-198.e2. [doi: 10.1016/j.japh.2017.11.003] [Medline: 29249652]

18. Stephan LS, Dytz Almeida E, Guimaraes RB, Ley AG, Mathias RG, Assis MV, et al. Processes and Recommendations for Creating mHealth Apps for Low-Income Populations. JMIR Mhealth Uhealth 2017 Apr 03;5(4):e41 [FREE Full text] [doi: 10.2196/mhealth.6510] [Medline: 28373155]

19. Miller DP, Weaver KE, Case LD, Babcock D, Lawler D, Denizard-Thompson N, et al. Usability of a Novel Mobile Health iPad App by Vulnerable Populations. JMIR Mhealth Uhealth 2017 Apr 11;5(4):e43 [FREE Full text] [doi: 10.2196/mhealth.7268] [Medline: 28400354]

20. Gordon M, Henderson R, Holmes JH, Wolters MK, Bennett IM, SPIRIT (Stress in Pregnancy: Improving Results with Interactive Technology) Group. Participatory design of ehealth solutions for women from vulnerable populations with perinatal depression. J Am Med Inform Assoc 2016 Jan;23(1):105-109 [FREE Full text] [doi: 10.1093/jamia/ocv109] [Medline: 26342219]

21. The Best Diabetes Apps of 2022. Healthline. URL: https://www.healthline.com/health/diabetes/ top-iphone-android-apps\#mysugr [accessed 2020-05-20]

22. The Best Quit Smoking Apps of 2020. Healthline. URL: https://www.healthline.com/health/quit-smoking/ top-iphone-android-apps [accessed 2020-05-20]

23. Santo K, Richtering SS, Chalmers J, Thiagalingam A, Chow CK, Redfern J. Mobile Phone Apps to Improve Medication Adherence: A Systematic Stepwise Process to Identify High-Quality Apps. JMIR Mhealth Uhealth 2016 Dec 02;4(4):e132 [FREE Full text] [doi: 10.2196/mhealth.6742] [Medline: 27913373]

24. Zhang J, Brackbill D, Yang S, Becker J, Herbert N, Centola D. Support or competition? How online social networks increase physical activity: A randomized controlled trial. Prev Med Rep 2016 Dec;4:453-458 [FREE Full text] [doi: 10.1016/j.pmedr.2016.08.008] [Medline: 27617191]

25. Stowell E, Lyson M, Saksono H. Designing and evaluating mHealth interventions for vulnerable populations: A systematic review. 2018 Presented at: CHI '18: CHI Conference on Human Factors in Computing Systems; April 21-26, 2018; Montreal, QC. [doi: 10.1145/3173574.3173589]

26. Stoyanov SR, Hides L, Kavanagh DJ, Zelenko O, Tjondronegoro D, Mani M. Mobile app rating scale: a new tool for assessing the quality of health mobile apps. JMIR Mhealth Uhealth 2015 Mar 11;3(1):e27 [FREE Full text] [doi: 10.2196/mhealth.3422] [Medline: 25760773]

27. Anderson K, Burford O, Emmerton L. Mobile Health Apps to Facilitate Self-Care: A Qualitative Study of User Experiences. PLoS One 2016;11(5):e0156164 [FREE Full text] [doi: 10.1371/journal.pone.0156164] [Medline: 27214203]

28. Higgins JP. Smartphone Applications for Patients' Health and Fitness. Am J Med 2016 Jan;129(1):11-19. [doi: 10.1016/j.amjmed.2015.05.038] [Medline: 26091764]

29. Arora S, Peters AL, Agy C, Menchine M. A mobile health intervention for inner city patients with poorly controlled diabetes: proof-of-concept of the TExT-MED program. Diabetes Technol Ther 2012 Jun;14(6):492-496. [doi: 10.1089/dia.2011.0252] [Medline: 22524591] 
30. Cordova D, Bauermeister JA, Fessler K, Delva J, Nelson A, Nurenberg R, Youth Leadership Council. A Community-Engaged Approach to Developing an mHealth HIV/STI and Drug Abuse Preventive Intervention for Primary Care: A Qualitative Study. JMIR Mhealth Uhealth 2015 Dec 18;3(4):e106 [FREE Full text] [doi: 10.2196/mhealth.4620] [Medline: 26685288]

31. Stephan LS, Dytz Almeida E, Guimaraes RB, Ley AG, Mathias RG, Assis MV, et al. Processes and Recommendations for Creating mHealth Apps for Low-Income Populations. JMIR Mhealth Uhealth 2017 Apr 03;5(4):e41 [FREE Full text] [doi: 10.2196/mhealth.6510] [Medline: 28373155]

32. Tamony P, Holt R, Barnard K. The Role of Mobile Applications in Improving Alcohol Health Literacy in Young Adults With Type 1 Diabetes: Help or Hindrance? J Diabetes Sci Technol 2015 Aug 06;9(6):1313-1320 [FREE Full text] [doi: 10.1177/1932296815588559] [Medline: 26251369]

33. Buchholz SW, Ingram D, Wilbur J, Pelt P. Using photos to develop text messages to promote walking. J Nurs Scholarsh 2013 Dec;45(4):380-387. [doi: 10.1111/jnu.12043] [Medline: 23870429]

34. Burner ER, Menchine MD, Kubicek K, Robles M, Arora S. Perceptions of successful cues to action and opportunities to augment behavioral triggers in diabetes self-management: qualitative analysis of a mobile intervention for low-income Latinos with diabetes. J Med Internet Res 2014 Jan 29;16(1):e25 [FREE Full text] [doi: 10.2196/jmir.2881] [Medline: 24476784]

35. Connelly K, Siek KA, Chaudry B, Jones J, Astroth K, Welch JL. An offline mobile nutrition monitoring intervention for varying-literacy patients receiving hemodialysis: a pilot study examining usage and usability. J Am Med Inform Assoc 2012;19(5):705-712 [FREE Full text] [doi: 10.1136/amiajnl-2011-000732] [Medline: 22582206]

36. Wen K, Miller SM, Kilby L, Fleisher L, Belton TD, Roy G, et al. Preventing postpartum smoking relapse among inner city women: development of a theory-based and evidence-guided text messaging intervention. JMIR Res Protoc 2014 Apr 03;3(2):e20 [FREE Full text] [doi: 10.2196/resprot.3059] [Medline: 24698804]

37. Chaudry B, Connelly K, Siek K, Welch J. The design of a mobile portion size estimation interface for a low literacy population. 2011 Presented at: 5th International ICST Conference on Pervasive Computing Technologies for Healthcare; May 23-26, 2011; Dublin. [doi: 10.4108/icst.pervasivehealth.2011.246113]

38. Nundy S, Mishra A, Hogan P, Lee SM, Solomon MC, Peek ME. How do mobile phone diabetes programs drive behavior change? Evidence from a mixed methods observational cohort study. Diabetes Educ 2014;40(6):806-819 [FREE Full text] [doi: 10.1177/0145721714551992] [Medline: 25278512]

39. Segall N, Saville J, L'Engle P, Carlson B, Wright MC, Schulman K, et al. Usability evaluation of a personal health record. AMIA Annu Symp Proc 2011;2011:1233-1242 [FREE Full text] [Medline: 22195184]

40. Tirado M. Role of mobile health in the care of culturally and linguistically diverse US populations. Perspect Health Inf Manag 2011 Jan 01;8:1e [FREE Full text] [Medline: 21307988]

41. Schnall R, Bakken S, Rojas M, Travers J, Carballo-Dieguez A. mHealth Technology as a Persuasive Tool for Treatment, Care and Management of Persons Living with HIV. AIDS Behav 2015 Jun;19 Suppl 2:81-89 [FREE Full text] [doi: 10.1007/s10461-014-0984-8] [Medline: 25572830]

42. Grimes A, Bednar M, Bolter J, Grinter R. EatWell: sharing nutrition-related memories in a low-income community. 2008 Presented at: CSCW08: Computer Supported Cooperative Work; November 8-12, 2008; San Diego, CA. [doi: $10.1145 / 1460563.1460579]$

\section{Abbreviations \\ ADA: Americans with Disabilities Act \\ mHealth: mobile health}

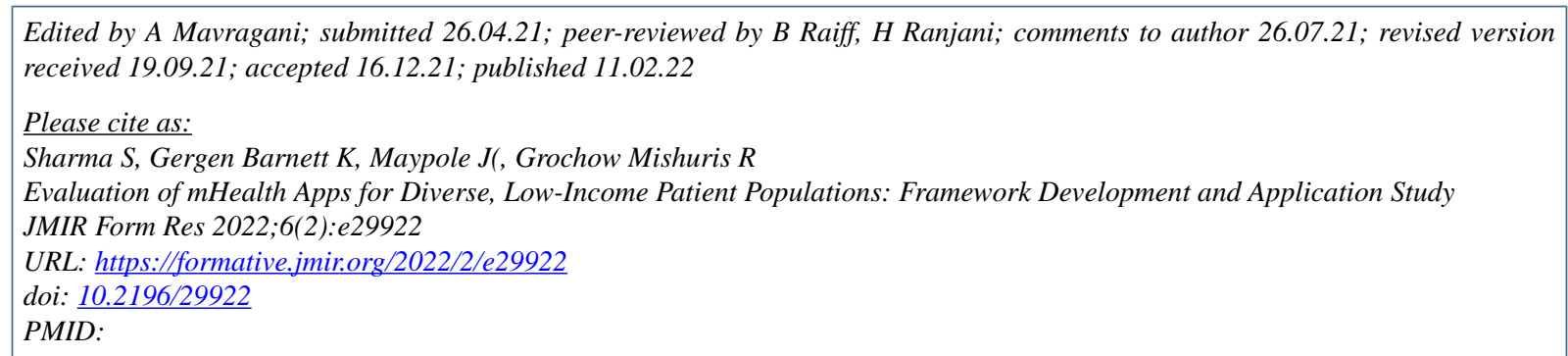

(CShreya Sharma, Katherine Gergen Barnett, John (Jack) Maypole, Rebecca Grochow Mishuris. Originally published in JMIR Formative Research (https://formative.jmir.org), 11.02.2022. This is an open-access article distributed under the terms of the Creative Commons Attribution License (https://creativecommons.org/licenses/by/4.0/), which permits unrestricted use, distribution, 
and reproduction in any medium, provided the original work, first published in JMIR Formative Research, is properly cited. The complete bibliographic information, a link to the original publication on https://formative.jmir.org, as well as this copyright and license information must be included. 